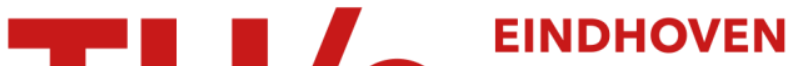 UNIVERSITY OF TECHNOLOGY
}

\section{Considerations on design optimization criteria for windows providing low energy consumption and high visual comfort}

\section{Citation for published version (APA):}

Ochoa Morales, C. E., Aries, M. B. C., Loenen, van, E. J., \& Hensen, J. L. M. (2012). Considerations on design optimization criteria for windows providing low energy consumption and high visual comfort. Applied Energy, 95, 238-245. https://doi.org/10.1016/j.apenergy.2012.02.042

DOI:

10.1016/j.apenergy.2012.02.042

Document status and date:

Published: 01/01/2012

\section{Document Version:}

Accepted manuscript including changes made at the peer-review stage

\section{Please check the document version of this publication:}

- A submitted manuscript is the version of the article upon submission and before peer-review. There can be important differences between the submitted version and the official published version of record. People interested in the research are advised to contact the author for the final version of the publication, or visit the $\mathrm{DOI}$ to the publisher's website.

- The final author version and the galley proof are versions of the publication after peer review.

- The final published version features the final layout of the paper including the volume, issue and page numbers.

Link to publication

\section{General rights}

Copyright and moral rights for the publications made accessible in the public portal are retained by the authors and/or other copyright owners and it is a condition of accessing publications that users recognise and abide by the legal requirements associated with these rights.

- Users may download and print one copy of any publication from the public portal for the purpose of private study or research.

- You may not further distribute the material or use it for any profit-making activity or commercial gain

- You may freely distribute the URL identifying the publication in the public portal.

If the publication is distributed under the terms of Article 25fa of the Dutch Copyright Act, indicated by the "Taverne" license above, please follow below link for the End User Agreement:

www.tue.nl/taverne

Take down policy

If you believe that this document breaches copyright please contact us at:

openaccess@tue.nl

providing details and we will investigate your claim. 


\title{
Considerations on design optimization criteria for windows providing low energy consumption and high visual comfort
}

\author{
Carlos E. Ochoa ${ }^{*}$, Myriam B.C. Aries, Evert J. van Loenen and Jan L.M. Hensen \\ Department of the Built Environment, Eindhoven University of Technology \\ P.O. Box 513, 5600 MB, Eindhoven, the Netherlands
}

\begin{abstract}
$\underline{\text { Abstract }}$
Apparent window size contradictions arise when optimizing simultaneously for low energy (small sizes) and visual comfort (large sizes). Diverse multi-objective optimization methods exist, but basic questions must be solved beforehand such as choosing appropriate evaluation measures. This work aims to determine the suitability of combined optimization criteria on window sizing procedures for low energy consumption with high visual comfort and performance.
\end{abstract}

The paper showcases diverse measures available to valorise energy consumption and visual aspects. A series of energy and visual criteria were selected, defining acceptance thresholds for dynamic evaluations. Whole-building computer simulations were performed on a standardized office located in a temperate climate. Discrete window-to-wall ratio variations were studied to demonstrate how these criteria affect the solution space.

Results were classified using a graphical optimization method, obtaining a solution space satisfying both energy and visual requirements. Most project expectations can be met within the range of sizes. However, unprotected windows barely meet acceptance criteria, needing additional control devices. Applying various related criteria with adequate values increases the diversity of acceptable solutions but too many limits it. Clear objectives and acceptance ranges have to be conceptualized in order to translate them into decisions. This becomes important when involving team design.

Keywords: building energy performance; optimization criteria; window size; visual performance; visual comfort

\section{Introduction}

Windows characterize energy use and visual comfort patterns in buildings. Choosing their areas and proportions is part of fundamental early design stage decisions, which are hard to change later. Therefore, window dimensions must result from a careful process and be part of an integral

\footnotetext{
* Corresponding author. Tel: +(31)40-2472302. Email: c.e.ochoa@tue.nl
} 
design process, considering multiple aspects at the same time. In addition, new building standards and certifications push for maximum performance in multiple aspects. Nevertheless, apparent sizing contradictions occur when minimizing energy consumption (smaller window sizes) but maximizing visual aspects (larger window sizes). Although optimization can be used to reach a solution, the main focus of the article is how to adequately use energy and visual criteria in order to achieve a balance regardless of the method used.

Single objective optimization of a building component is found frequently in the literature. Examples include obtaining high visual performance [1], or lower energy consumption [2-6]. Other studies tried to demonstrate that single objective optimization of window areas could help to achieve both low energy use and high visual performance [7].

High degrees of complexity are introduced by considering simultaneously multiple objectives in an almost infinite number of possible design solutions. One such case occurs in facade design. In light of this, multi-objective optimization techniques start to be applied in building science. They are used as decision tools to determine a set of solutions that satisfy (or are close to satisfying) a given problem with numerous requirements [8].

A detailed examination of optimization methods reveals fundamental dilemmas when applying evaluation criteria, which need to be answered beforehand by designers. For example, using different assessment criteria to a single aspect of the same problem can lead to diverse valid solutions, requiring introduction of new additional criteria [9].

Each criterion in the evaluation set can have different importance values [10-11] assigned according to expectations from users, project investors or experiences with a given system [12]. Daylighting systems are evaluated through indicators for illuminance and glare [13] in static or dynamic situations. Optimizing daylight aspects is important as they influence energy consumption through supplementary artificial lighting, while solar radiation affects cooling and heating systems performance [14], as shown in Fig. 1.

Recent whole-building and coupled computer simulation tools have become accessible to evaluate at once both energy and visual aspects of building design. This type of simulation is used here to examine a standardized prototype with variable window size, stressing how the solution space is affected by different optimization criteria. Simulations were examined for temperate climates but the procedure can be applied to different locations. 


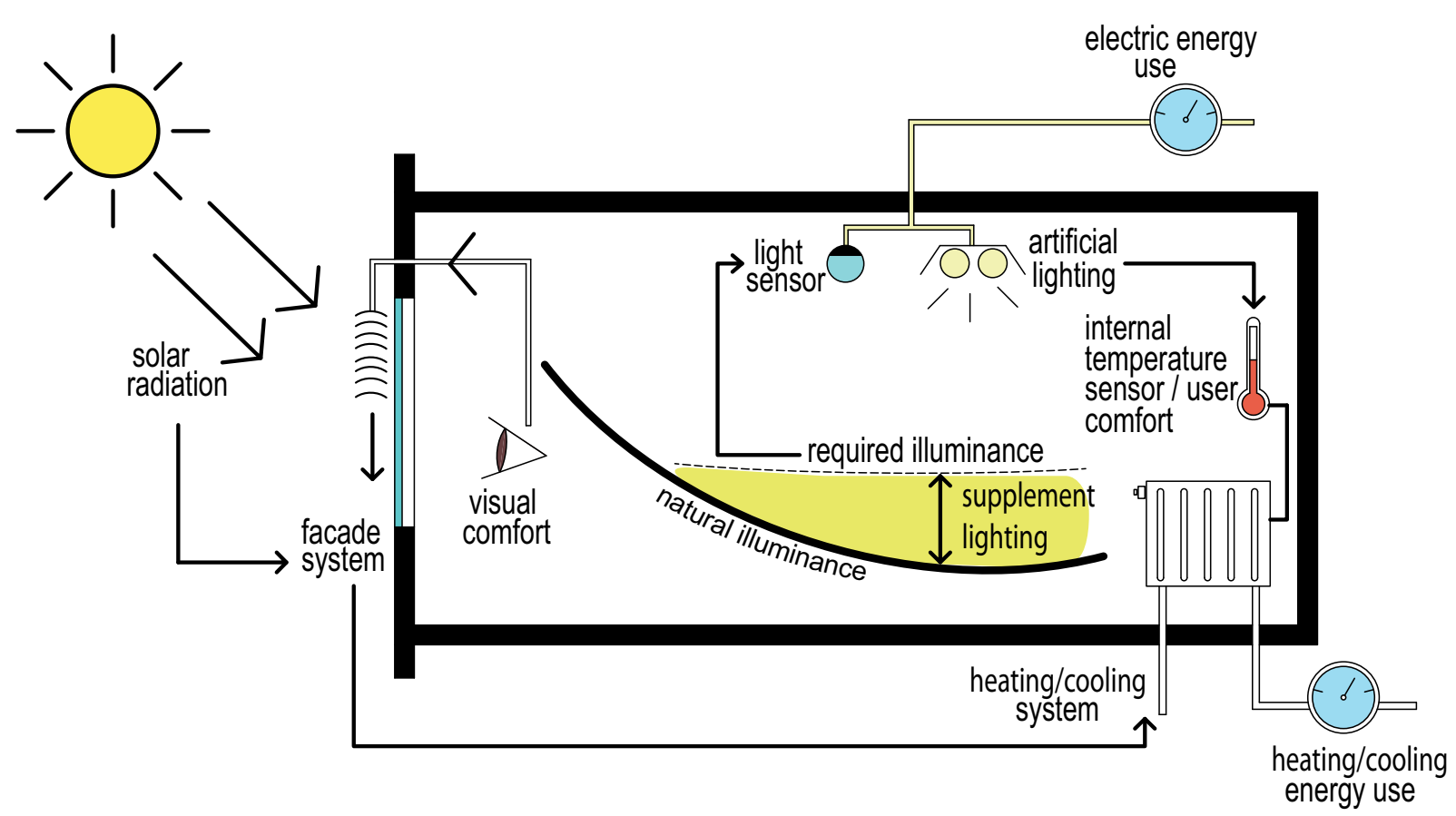

Figure 1. Influence of daylight on heating, cooling and artificial lighting systems

\section{$\underline{\text { 2. Available visual and energy evaluation criteria }}$}

Section 2.1 briefly reviews previous work examining simultaneously energy and visual aspects for windows and fenestration systems. Section 2.2 reviews in detail some of the criteria used, emphasizing visual evaluation ones due their impact on energy consumption.

\subsection{Examples of simultaneous evaluations for energy and visual aspects}

Simple vertical daylight openings are usually taken as the starting point to analyze integration of visual characteristics and energy consumption. One example is a parametric study using wholebuilding simulation and scale models for two climate types in the UK and Brazil [7]. That study aimed to determine a function of window sizes and room indexes providing minimal electric lighting consumption and maximal daylight use. Visual aspects were examined through the daylight factor. Even though, applying their recommendations is complex, some window sizes and their locations do not provide view. The cases are too simplified for some situations, while local building codes now require increased minimal insulation values.

A similar examination has been made for a Canadian climate [15]. Discrete window size variations from $0 \%$ to $100 \%$ window-to-wall ratio (WWR) were considered for a test room. Energy consumption and average daylight availability ratios were calculated. Optimal window 
areas were those in the "critical region". This term defines the limit when increasing window size does not contribute any more to daylight availability [16]. Calculation of the daylight availability ratio, however, is difficult without detailed long-term meteorological data.

A computer simulation study was made in a Dutch climate; window location and area were changed in $10 \%$ steps on a fixed prototype space [17]. That research found window placement affects lighting energy consumption through changes in natural light distribution on switching sensors. It also found that window sizes beyond $50 \%$ facade area did not decrease artificial lighting loads for a given illuminance setpoint. Automatic controls were recommended.

Specialized vertical daylight systems are also examined by considering simultaneously energy consumption, daylight distribution and visual performance. Whole-building simulation was used to analyze electrochromic glazing and switching strategies on a window divided in a lower and upper opening of constant dimensions 30 and 60\% WWR with overhang between them [18]. Yearly averages for glare, illuminance and energy consumption were calculated. In another study, a model incorporating whole-building simulation was proposed for the design of dynamic solar shading elements on variable window sizes [19]. Illuminance, glare and energy were calculated simultaneously and compared in order to comply with an energy rating building code. Effects on visual performance and comfort were given for critical dates only.

\subsection{Energy and visual performance evaluation criteria}

a) Energy performance criteria

These criteria usually quantify the consumption of different items such as heating, cooling, lighting and ventilation energy. The possibility exists to measure them on site after system commissioning, and thus compare them to estimated amounts. They can be expressed in terms of energy units ( $\mathrm{kWh}$ or GJ) per unit area per time unit. Typically the goal is to select the least energy-consuming system, which is useful to obtain an energy certification or label, such as BREEAM or LEED or to comply with local and national building energy codes such as the Dutch Building Decree [20]. An alternate way to calculate energy performance and demand, related to weather conditions, is through the degree days method [21].

User comfort can also be used to evaluate energy performance, using different indexes and predictive methods. Some are detailed on Table 1. Thermally adaptive comfort is being used as a new way to express energy performance, but requires further improvement of thermal adaptability and sensation in buildings with different climatic systems [22].

b) Visual performance and comfort criteria: quantity and quality

Building occupants are exposed simultaneously to different kinds of stimuli. However, it has been noted that discomfort due to visual effects (glare, headaches, deregulation of the circadian 
rhythm leading to depression) is more frequently reported than discomfort by thermal effects, due to the time delay in experiencing the latter and thus being important in building design due to the possible rejection by users of the built environment due to its influence on their overall health [23]. In this article, visual performance and comfort criteria will be divided into illuminance-based and glare-based criteria as they need separate consideration when measuring visual satisfaction in the work environment [24].

Illuminance-based criteria describe the performance of a lighting system in terms of the amount of light necessary to carry out a task, usually on the horizontal plane. Suitable absolute numbers are provided in various standards and design guides. For example, 5001x is recommended at the horizontal workplane in order to perform office tasks (NEN-EN 12464-1:2011). Natural light below these levels usually implies use of artificial lighting in order to supplement them.

A classical illuminance-based indicator such as the daylight factor (DF) has been subject to criticism. Although useful when comparing designs, it is meaningful only for overcast sky conditions, lacks consideration for illuminance task values and building orientations. Fulfilling minimum DF requirements can sometimes bring conflicts with visual and thermal comfort requirements [25]. New performance metrics have been proposed in order to overcome DF limitations, such as the daylight autonomy (DA) and the continuous daylight autonomy (DAcon) [26] but still need further benchmarking under different contexts.

Natural light variations inside a room can reach extreme sharp contrasts. This quality can be described through illuminance uniformity ratios. It is an important measure since human vision is more sensitive to contrasts than to light amounts, although there is higher tolerance to contrasts from natural lighting [27]. A well designed non-uniform lit space provides information and interest to users. Uniformity will be understood here as the ratio between maximum and minimum illuminance inside a space.

More literature is available on acceptable uniformity from artificial sources than from daylighting, with values being under constant revision. For instance, CIBSE in 1987 recommended uniformity from all sources to be less than or equal to 1:3, with supplementary lighting compensating differences from natural light [27]. In 2006, it introduced new definitions for uniformity and diversity [28]. Diversity follows the definition used here for uniformity, recommended not to exceed 1:5 for natural lighting and 1:3 for artificial lighting. The IESNA also recommended 1:3 for artificial sources [29]. The BREEAM 2008 assessment method [30] defines uniformity like CIBSE, specifying the daylight ratio between average illuminance at task and immediate surroundings as 1:2.5.

However, uniformity ratios by themselves do not provide an indication of useful illumination levels. Both must be considered together with their distribution on the horizontal plane of a space [31]. Useful illuminances range from 100 to $2000 \mathrm{~lx}$, in order to provide variability in a room but at the same time avoid thermal discomfort [32]. 
Glare-based criteria are meant to characterize a lighting system based on visual comfort. Glarecorrecting elements such as blinds influence energy consumption as users supplement visual tasks with artificial lighting. A comprehensive account of glare indexes and their limitations is detailed by [33] and [34]. The starting point for glare indexes has been luminance values and position indexes, since human vision works closer to that concept [35]. Luminance ratios have been proposed, such as 1:4 between task area and surroundings for work environments [29].

Glare indexes are meaningful only when comparing lighting systems. Index points are usually expressed in semantic rather than absolute terms. Even though, no single glare measure is universally accepted, nor can be applied to every lighting source as eye adaptation changes [33]. A variety of glare indexes exists for artificial lighting, such as the Unified Glare Rating (UGR). Regarding natural light, one of the most widely used is the Daylight Glare Index (DGI). It is an open dimensionless scale, where a value of 22 is assigned to the evaluation "just acceptable" [36]. Limitations exist, but corrections have been proposed [37]. A window sizing procedure based on DGI has been suggested [38], but the method is static and needs calculation of multiple sizes for each time step. Recent propositions for daylight glare assessments include scene analysis through digital cameras, and models such as the daylight glare probability (DGP) [39].

c) Dynamic evaluation metrics

The application of current energy, illuminance- and glare-based evaluation criteria can be extended to dynamic yearly performance evaluations. Statistical measures such as global averages can be used, but these can mask severe occurrences of an indicator [18]. A second option is to calculate data for representative time segments, based on weather files containing detailed information on solar radiation and position, outdoor temperature, etc. [40]. Afterwards, the number of time steps where a specified condition is met can be added up and compared with other designs. However, research needs to be done on minimal user acceptance requirements using this method.

A summary of evaluation criteria for both energy and visual aspects is given on Table 1. 
Accepted for publication in Applied Energy

\begin{tabular}{|c|c|c|}
\hline & Energy aspects & Visual aspects \\
\hline \multirow[t]{3}{*}{ Performance } & Consumption & Illuminance \\
\hline & Degree days & \\
\hline & Adaptive comfort & \\
\hline \multirow[t]{5}{*}{ Comfort } & $\begin{array}{l}\text { Predictive mean vote } \\
\text { (different indexes) }\end{array}$ & Uniformity \\
\hline & $\begin{array}{l}\text { Predicted temperature and } \\
\text { RH }\end{array}$ & Contrast \\
\hline & & Daylight glare index \\
\hline & & Daylight glare probability \\
\hline & & $\begin{array}{l}\text { Other glare indexes (artificial } \\
\text { lighting) }\end{array}$ \\
\hline \multirow{3}{*}{$\begin{array}{l}\text { Thermal and visual } \\
\text { dynamic evaluations }\end{array}$} & \multicolumn{2}{|l|}{ Time condition is met } \\
\hline & \multicolumn{2}{|c|}{ Averages (yearly, monthly, etc) } \\
\hline & \multicolumn{2}{|c|}{ Usable range (maximum-minimum) } \\
\hline
\end{tabular}

Table 1. Different criteria in use for thermal and visual comfort and performance evaluations

\section{Evaluation method used}

\subsection{Location and climate type description}

The computer model was evaluated for the climate of Amsterdam, the Netherlands $\left(52.3^{\circ} \mathrm{N}\right.$, $4.8^{\circ} \mathrm{E}$ ) using the IWEC file. It is usually described in the Köppen scale as $\mathrm{Cfb}$. It characterizes cool summers and moderate winters, with precipitation distributed throughout the year. There are about 1524 sunshine hours per year. Average winter daytime temperatures for that locale range between $2-6^{\circ} \mathrm{C}$, with minima below freezing point not being rare. During summer this range is $15-22^{\circ} \mathrm{C}$, although maxima of $>35^{\circ} \mathrm{C}$ have been recorded [41]. 


\subsection{Test room description}

In order to highlight how different optimization criteria affect the solution space, the IEA Task 27 reference office was used as basis. It has been described extensively by [42] [43] for its typical occupancy and load situations for a cellular office, together with window descriptions. For the sake of brevity, the reader can consult these references for specific data on the reference office. This was modelled using EnergyPlus as whole-building simulation program due to its ability to provide an integrated and simultaneous solution to the building analysis [44]. Insulation values at the opaque section of the external wall were upgraded to comply with current office buildings standards (U-value $0.32 \mathrm{~W} / \mathrm{m}^{2} \mathrm{~K}$, according to the Dutch building standard NEN 2916:2004). The rest of components are assumed adiabatic since using lightweight partitions has become the most widespread solution for commercial buildings and provides a way to express building energy usage per square metre. In order to focus on the performance of our method rather than the details of specific HVAC systems, the "Ideal Loads Air System" of EnergyPlus was used. The module consists of a hypothetical office room (dimensions $3.5 \times 5.3 \times 2.7 \mathrm{~m}$ ) with a single external wall (Fig 2). Lighting density was nominal 4x50W mounted ceiling lamps. Visual properties of the surfaces, and thermal loads conditions such as ventilation and occupancy schedules, are as in the reference office. The external wall accommodates a single window opening placed at its centre, in order to provide outside view at all times. The WWR of the opening varied from $10 \%$ to $100 \%$ in $10 \%$ discrete steps (Fig. 3). The four main orientations were evaluated.

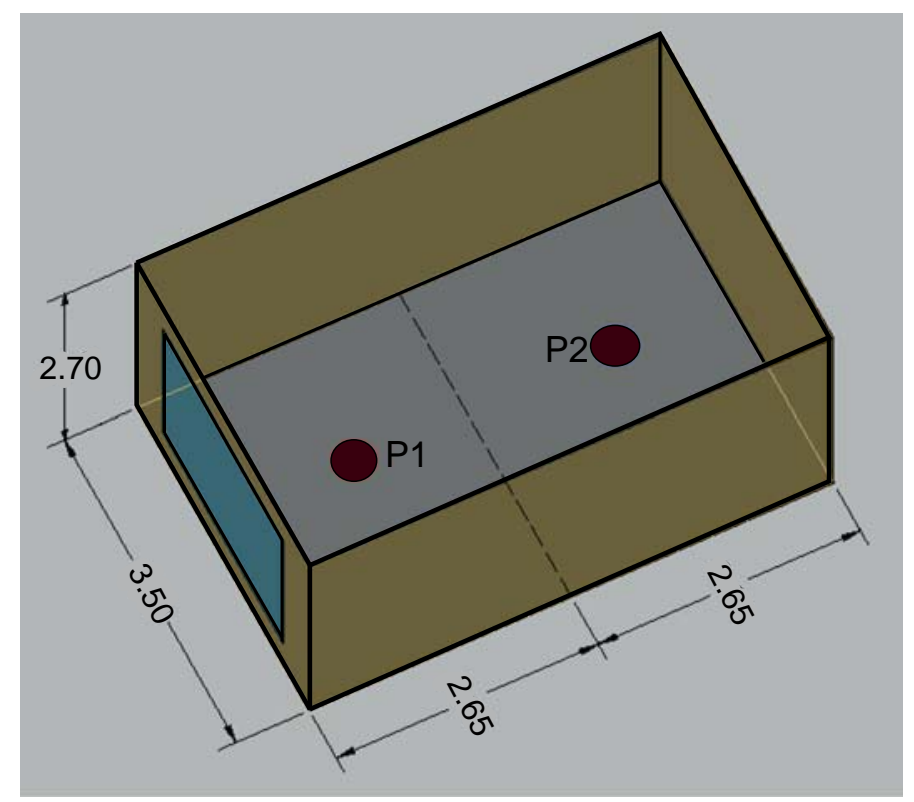

Figure 2. Test room description summary. P1 and P2 represent lighting zone control points and are placed at the centre of each zone at $0.80 \mathrm{~m}$ from the floor plane. Dimensions in metres. 
Since this study focuses on evaluating optimization criteria, glazing in all window sizes was double pane clear, without any shading device (U-value at centre $1.7 \mathrm{~W} / \mathrm{m}^{2} \mathrm{~K}$ ). Electric lighting was controlled through a two-zoned automatic dimmer, supplementing natural light at the working plane $(0.8 \mathrm{~m}$ from the floor). Normal office tasks were assumed to be done with an illuminance target level of 5001x, as stated in NEN-EN 12464-1:2011. Illuminance was measured at two control points, which correspond to the centre of each lighting zone. The control point closer to the window was designated P1, while P2 is the one closer to the back of the room. DGI glare was measured at P2, with the viewpoint looking directly to the window (Fig. 2). Although $\mathrm{P} 1$ is a worst-case in terms of glare, $\mathrm{P} 2$ was selected as a performance indicator for both qualitative and quantitative visual criteria affecting energy consumption. It can be argued that controlling glare at P1 is easier through adequate devices, but without careful design these could hinder lighting levels from natural sources at P2, requiring artificial lighting to compensate (for example, when blinds are totally closed).
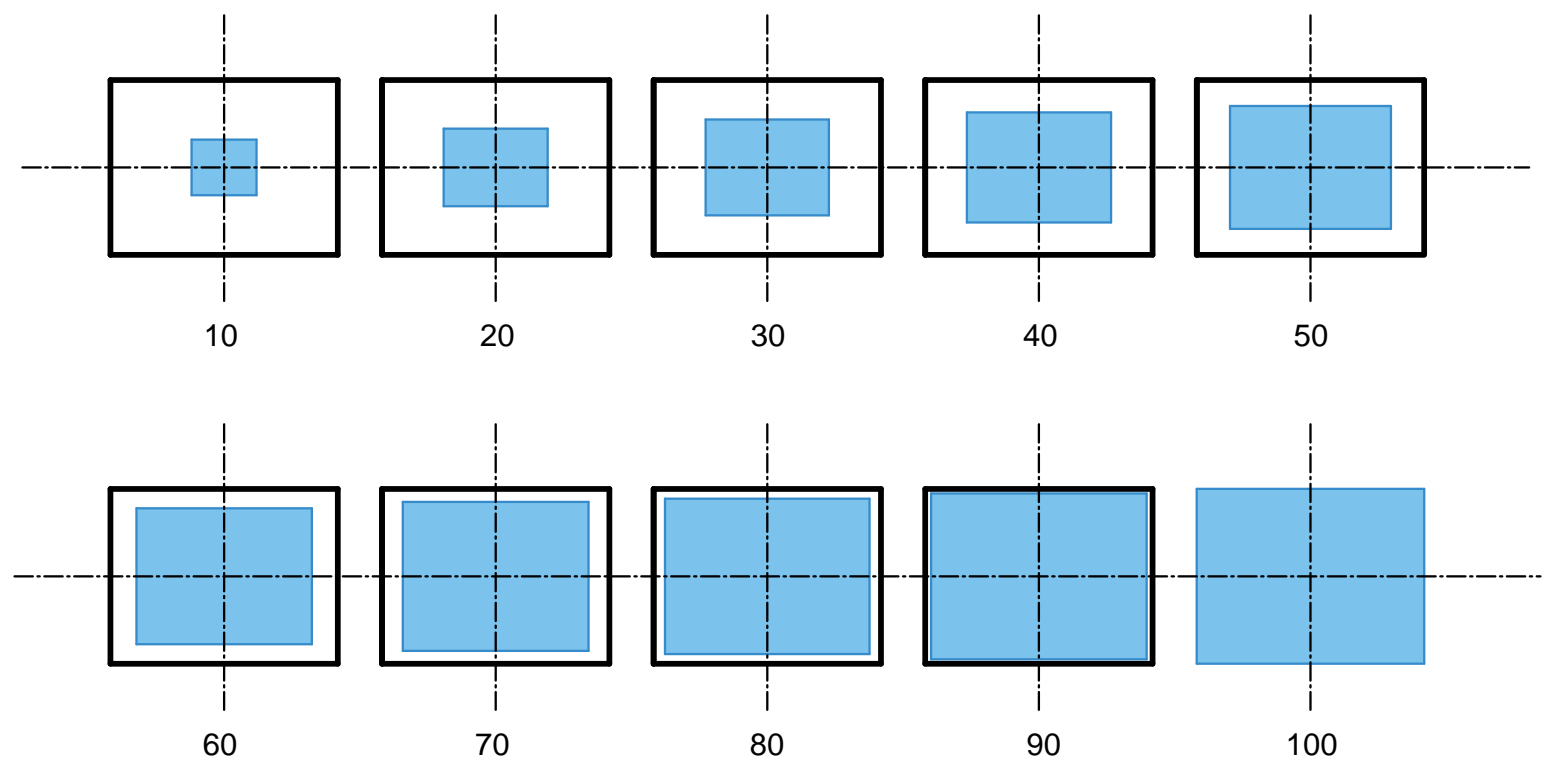

Figure 3. Examined window size variations. Amounts expressed in percentage window-to-wall ratio (WWR).

\subsection{Evaluation criteria for optimization}

Visual and energy performance assessments of different window sizes were made using the criteria of Table 2. Energy consumption evaluation benchmarks included minimal heating, cooling, ventilation and artificial lighting. Illuminance was chosen as a quantitative indicator for visual aspects. Regarding qualitative measures for visual comfort, two types of criteria were tested. The first was uniformity (average yearly illuminance P1/ average yearly illuminance P2). 
The second was glare, evaluated through DGI at P2. This index can be calculated from one point, making it consistent with the illuminance reference point.

Although dynamic metrics exist and can be expressed in different ways [39], there is little or no research on minimal acceptance criteria using time-based performance metrics. In theory, buildings should provide comfort and respond to user needs $100 \%$ of occupancy time. Nevertheless, it is common engineering practice to accept that this option will not be possible or feasible to choose. Thus an acceptance rate must be proposed according to the priority of objectives to be achieved [45]. Detailed procedures exist to determine such value, but a simplified approach is taken here. Due to its low sophistication, we assume for the system under study $50 \%$ visual comfort and performance satisfaction time during occupancy. Naturally, more complex systems bring higher expectations on satisfaction and performance.

The acceptance criteria using dynamic simulations are detailed below, providing boundaries to the solution space. Abbreviations in italics refer to the notation used in equations (1) to (4):

a) Combined yearlong energy consumption had to be minimized (En) (1). Artificial lighting energy is used to relate total energy use with visual criteria. In this sense, the lower boundary is minimal consumption for all items, and the upper one is the "critical region" where daylight does not contribute to artificial lighting savings [16].

En is subject to:

b) Illuminance at $\mathrm{P} 2$ had to be equal to or exceed 5001x for a minimum of $50 \%$ total occupancy hours $(E)$. (2)

c) Daylight glare, when looking directly to the window from P2, had to be equal to or less than DGI 22 for a minimum of 50\% total occupancy hours $(G)$. Only this viewing direction was considered. (3)

d) Illuminance uniformity (Ep2/Ep1) had to be equal to or less than 3.5 for a minimum of $50 \%$ total occupancy hours $(U)$, based on the fact that there is higher tolerance to daylight contrast than to artificial lighting. (4)

e) For this research, accomplishing illuminance criteria and one visual comfort criteria (uniformity or glare) were deemed sufficient to accept a window size into the solution space.

Compliance of a given criteria during all occupancy hours is unity. If the desired energy consumption criterion is represented by $E n$, glare criteria as $G$, illuminance criteria as $E$, and uniformity criteria as $U$, then the optimization problem can be formulated as follows:

Minimize $\quad E n$

Subject to $\quad E \geq 0.5$ 


$$
\begin{aligned}
& G \geq 0.5 \\
& U \geq 0.5
\end{aligned}
$$

\begin{tabular}{|c|c|c|c|c|}
\hline Type of aspect & Element & Criteria & Unit & $\begin{array}{l}\text { Acceptance value } \\
\text { dynamic evaluation }\end{array}$ \\
\hline \multirow[t]{5}{*}{ Energy aspects } & \multirow[t]{5}{*}{ Performance } & $\begin{array}{l}\text { Total } \\
\text { consumption }\end{array}$ & \multirow[t]{5}{*}{$\mathrm{kWh} / \mathrm{m} 2$} & \multirow[t]{5}{*}{$\begin{array}{l}\text { Least energy } \\
\text { consumption }\end{array}$} \\
\hline & & $\begin{array}{l}\text { Heating } \\
\text { consumption }\end{array}$ & & \\
\hline & & $\begin{array}{l}\text { Cooling } \\
\text { consumption }\end{array}$ & & \\
\hline & & $\begin{array}{l}\text { Lighting } \\
\text { consumption }\end{array}$ & & \\
\hline & & $\begin{array}{l}\text { Artificial } \\
\text { ventilation }\end{array}$ & & \\
\hline \multirow[t]{3}{*}{ Visual aspects } & Performance & $\begin{array}{l}\text { Hours } \\
\text { illuminance at P2 } \\
\text { exceeds 5001x }\end{array}$ & lx & $\begin{array}{l}50 \% \text { of total time } \\
\text { during office } \\
\text { occupancy }\end{array}$ \\
\hline & \multirow[t]{2}{*}{ Comfort } & $\begin{array}{l}\text { Uniformity } \\
\text { P1/P2 }\end{array}$ & unitless & $\leq 3.5$ \\
\hline & & $\begin{array}{l}\text { Hours DGI at P2 } \\
\text { below } 22\end{array}$ & $\begin{array}{l}\text { Daylight } \\
\text { Glare Index } \\
\text { units }\end{array}$ & $\begin{array}{l}50 \% \text { of total time } \\
\text { during office } \\
\text { occupancy }\end{array}$ \\
\hline
\end{tabular}

Table 2. Summary of criteria that were tested. P1 represents a control point closer to the window, P2 a control point at the back of the room.

\section{$\underline{\text { 4. Simulation Results }}$}

Results for window size variations in the four main orientations are shown in Fig. 4. Energy consumption is shown in stacked bar graphs for heating, cooling, artificial lighting and 
ventilation energy. Visual comfort and performance curves present percentage of occupancy hours meeting uniformity, glare and illuminance criteria. A graphical optimization method was used in this research, to avoid the drawbacks of specific optimization algorithms and is used as follows: A shaded area in the graph covers below 50\% of occupancy hours. Any point in the discrete steps of the illuminance or glare curves outside this area represents a given visual criteria being met. It must be noted that results are valid for a room with the described conditions and dimensions, having a single opening placed in the centre of the facade with more or less the same proportions on each side. Due to the use of discrete (whole) size steps in the simulation, size selection is done in the same discrete steps as the WWR increments.
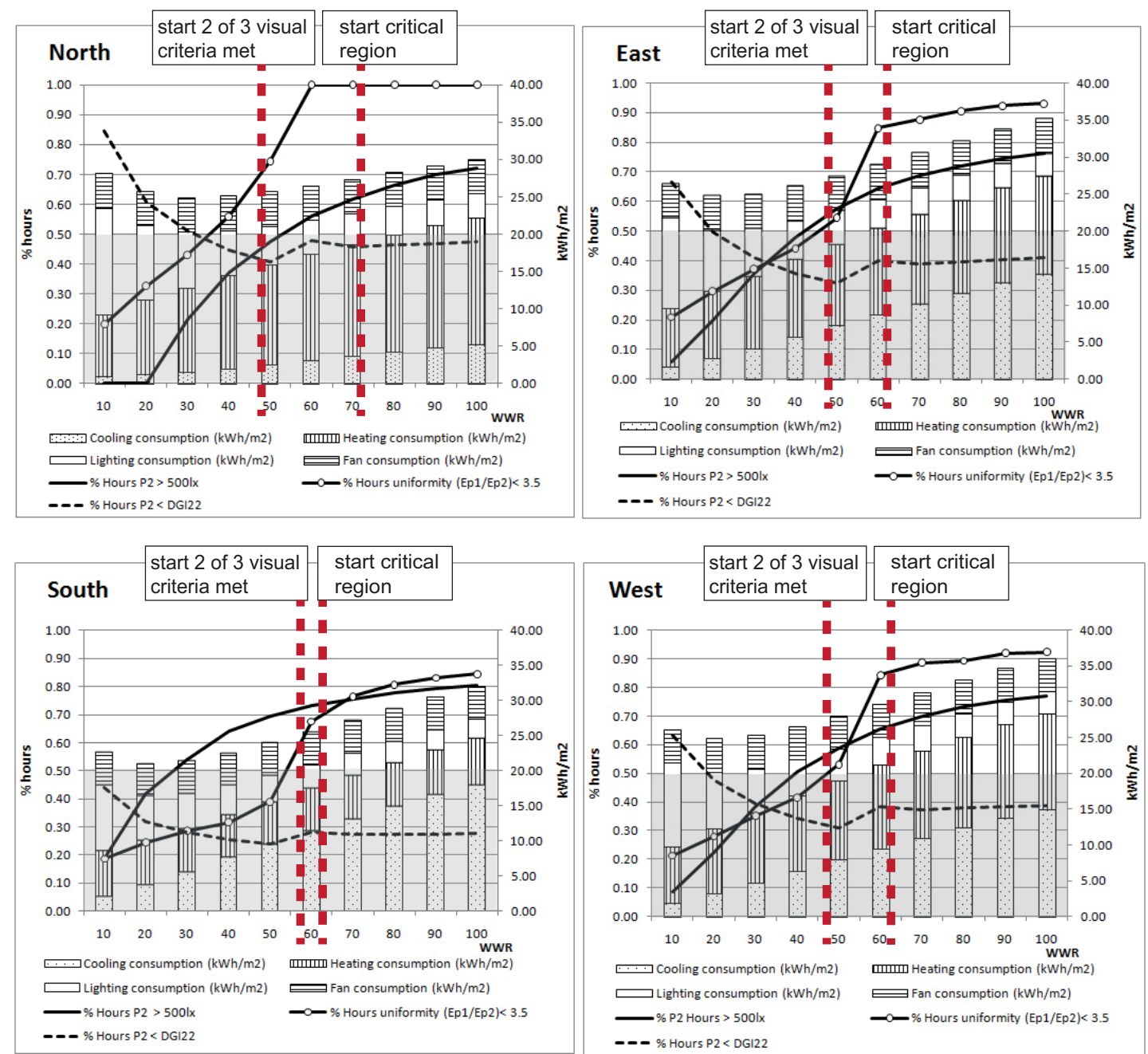

Fig 4. Solution space for energy use, visual performance and comfort of a hypothetical test room with variable WWR in Amsterdam, the Netherlands. The four main orientations are shown. Shaded graph areas represent visual criteria not met; vertical dashed lines indicate solution space boundaries. 
The energy consumption trend shows that in a temperate climate, using larger windows becomes counterproductive, since this provides larger areas for heat transfer during both winter and summer. This is seen in a larger cooling demand with larger window sizes for South orientation; while enlarging window sizes for North result in higher heating demand. However, as observed in the same graphs, window sizes cannot be reduced arbitrarily since electric lighting consumption becomes an issue, together with visual comfort. This makes the method presented in this article relevant. The highest global energy consumption was observed at East and West. The least energy use was observed at 30\% WWR for North, while at 20\% WWR for South, East and West orientations. However, solutions with least total energy consumption have the lowest visual performance. For those window sizes, required minimum 5001x illuminance at $\mathrm{P} 2$ is not met, nor uniformity and glare criteria.

Regarding electric lighting consumption, a "critical region" was observed. Reductions on electric lighting energy caused by daylight stop being significant compared to the previous case (less than 5\%). For North orientation, this was seen from 70\% WWR. For South, East and West this was observed from $60 \%$ WWR.

\subsection{Window size selection and compromise size}

Illuminance performance at P2 was deemed a requisite to be met, as it forms part of many standards and certifications. Achieving one of the two visual comfort criteria at P2 in addition to illuminance occurs for North: 50 to 100\% WWR, for South: 60 to 100\% WWR, for East and West: 50 to $100 \%$ WWR.

The solution space is delimited by the intersection between compliance with at least one visual comfort criteria, compliance with illuminance criteria and the start of the critical region. The window size range is then for North: 50 to $70 \%$ WWR, for South: $60 \%$ WWR, for East and West: 50 to $60 \% \mathrm{WWR}$.

Since typically only one window size can be selected using traditional building technologies, "higher level information" needs to be introduced [46]. This type of information fulfils other expectations involved in the design project, which are usually hard to quantify and not part of the original optimization problem. Larger WWRs respond to factors such as improving view, architectural image, etc. Smaller WWRs, on the other hand, address considerations such as tighter maintenance budgets, privacy, etc. If such objectives can be satisfied by a window size within the solution space defined above, a "compromise" can be reached where unquantifiable project expectations coincide with goals of low energy use and high visual performance and comfort, assuming they have equal values for the design team.

A simple application example can be considered. A designer wants to give the most views, but keep energy consumption minimal. The only restrain is that views are to the North. Using the evaluation criteria of section 3.3, the solution space for that orientation comprises window sizes between 50 to $70 \%$ WWR. Using maximal views as higher level information, the upper bound 
would be $70 \%$ WWR. Larger sizes are in the critical region, wasting electrical lighting energy and overall energy consumption. A window size below 50\% would use lower energy, but has unacceptable visual comfort and illuminance performance. Using the same logic of the example, recommended window sizes are then for each orientation: North $70 \%$, South $60 \%$, and for East and West $60 \%$.

\section{$\underline{\text { 5. Discussion }}$}

Energy use and task illuminance criteria were used to evaluate consumption patterns and compliance with building standards and certifications. Linking quantitative and qualitative criteria in the optimization procedure was done through visual comfort, using elements such as glare and illuminance uniformity.

Including diverse visual comfort criteria enabled selecting more valid alternatives had only one criterion been proposed. Although in principle it is desirable that all visual comfort criteria be fulfilled, the glare acceptance criterion was not met by any of the studied window variations. However, using illuminance uniformity as an additional visual comfort criterion allowed other valid solutions to be accepted.

Results show that optimizing window size for one objective can hinder attaining additional ones. Windows optimized exclusively for visual comfort produce large energy consumption patterns. This is consistent with results of [25]. Optimizing window size for low energy consumption only does not meet any of the predetermined visual acceptance criteria. For example, a $20 \%$ WWR window on the East achieves the lowest energy consumption for that orientation, but natural lighting complies with illuminance standards $30 \%$ of occupancy hours. This figure translates to an office environment dominated by high electric lighting usage.

Assuming a constant occupancy pattern during office hours that needs satisfying lighting requirements during its entirety, the increase in total energy use from the least energy-consuming window size to the next size meeting visual comfort and performance criteria is as follows: for North $3.25 \%$, for South $21 \%$, for East $11 \%$ and for West $13 \%$. Such increases not only meet building code illuminance requirements, but are an investment on elements adding value to a space. They include health benefits from visual comfort, improved user acceptance and productivity.

The solution space presents limited window size options for this particular configuration and climate type. The prototype already has high performance elements optimized for energy savings such as insulation thickness, dimming lighting control system, and luminaire zoning. This allowed us to optimize for window size only. Thus, starting a problem with too many predefined criteria can limit excessively the solution space. Introducing shading devices will increase the amount of possible solutions, but additional feature optimization is then required for each case. 
Results show that architectural propositions lacking visual control devices are problematic, since it is difficult for them to meet most evaluation criteria during the occupancy period. Therefore, a careful design process needs to takes into account climatic elements from the earliest design stages such as shading devices, adequate glazing types and adaptable personal visual comfort. Optimized building design requires specialists working together to regulate their objectives, setting tolerance amounts within their own goals.

\subsection{Further research}

Our research has brought questions that need to be solved through further research. These include the relative weight of visual performance and comfort criteria in a dynamic evaluation context. For the current analysis, equal importance was assigned to both due to the fact that both are important in maintaining the general well-being and health of users. Tasks will not be carried out efficiently if users feel constant visual discomfort, though their environment might accomplish the illuminance prescribed by the building code. This can lead to rejection by users of the built space or the application of unexpected corrective measures [19]. Task illuminance was chosen for performance as this is well documented, forming part of many building codes and certifications. It is thus expected to have an important weight in many evaluations, together with the fact that visual effects are experienced faster than thermal ones.

Difficulties arise when choosing visual comfort criteria. Uniformity ratios are derived from illuminance, but need corroboration for yearlong evaluations such as taking into account seasonal variations. Glare indexes have problems in their definition and applicability to light sources. Although new indicators could be applied (such as DGP) in order to overcome DGI limitations, both metrics need more research for use in time-dependent dynamic evaluations. Experimentation is needed to confirm how many visual comfort criteria must be included in multi-objective optimization procedures in order not to constrain solutions.

Another subject for further research is the percentage of time during occupancy that acceptance criteria have to be met. This applies not only for systems with different complexity, but also for different building and user profiles (e.g., geographical location, occupancy schedules, illuminance task requirements, etc). Due to the use of a representative module, results can be used in multi-storey buildings that comply with the described typology. Studies need to be carried out for extended cases such as shading devices and multiple openings in the same facade section.

It must be noted that integral design must take into account other objectives and criteria, such as view quality, acoustics and control over the environment [47], together with energy consumption and visual performance.

\section{Conclusions}


Window size has to be optimized for more than one objective, due to its influence on energy consumption and visual comfort. Goals have to be expressed through a set of clearly defined criteria which are closely related and that can be used in dynamic evaluations. It is proposed to use glare and illuminance uniformity as evaluation criteria for visual comfort; while taking energy consumption and illuminance to ensure meeting legal requirements and certifications.

In order to avoid the conflict brought by optimizing exclusively for energy saving or visual comfort, boundaries for a solution space are proposed meeting both requirements. The solution space provides the design team with options to choose from if their expectations for energy and visual comfort have equal value as those of project image (thus reaching a "compromise" between project expectations and final design). The use of such procedure is necessary since a solution which satisfies all users during their entire occupancy is not feasible or possible to choose, even with technologically complex features. Another precondition to using the procedure is that designers decide beforehand the number of related criteria to be met associated with the performed task. The method described here can be taken as an example on how to proceed when some criteria are not met.

However, it must be noted that the low complexity of the studied system presents difficulties in meeting the predefined criteria. Therefore, additional building elements such as blinds, shades and improved glazing must be considered to regulate solar radiation, light amounts and glare. The solution space will have different characteristics for other room proportions or settings, and when additional criteria for acoustics, thermal comfort, etc are included. As this study is a starting point into criteria considerations, it can be extended to other types of climates and additional building components.

\section{$\underline{\text { 7. References }}$}

[1] Greenup, P.J., Edmonds, I.R. Test room measurements and computer simulations of the micro-light guiding shade daylight redirecting device, Solar Energy, 2004;76: 99-109.

[2] Kusiak, A., Li, M., Tang, F. Modeling and optimization of HVAC energy consumption, Applied Energy, 2010; 87: 3092-3102.

[3] Nair, G., Mahapatra, K., Gustavsson, L., Implementation of energy-efficient windows in Swedish single-family houses, Applied Energy, 2012; 89: 329-338.

[4] Han, J., Lu, L., Yang, H., Numerical evaluation of the mixed convective heat transfer in a double-pane window integrated with see-through a-Si PV cells with low-e coatings, Applied Energy, 2010; 87: 3431-3437.

[5] Maheshwari, G.P., Al-Murad, R., Impact of energy-conservation measures on cooling load and air-conditioning plant capacity, Applied Energy, 2001; 69: 59-67. 
[6] Wan, K.K.W., Li, D.H.W., Pan, W., Lam, J.C., Impact of climate change on building energy use in different climate zones and mitigation and adaptation implications, Applied Energy DOI:10.1016/j.apenergy.2011.11.048.

[7] Ghisi, E., Tinker, J.A. An ideal window area concept for energy efficient integration of daylight and artificial light in buildings, Building and Environment, 2005; 40: 51-61.

[8] Erghott, M. Multicriteria optimization, 2nd Ed, Berlin: Springer; 2005.

[9] De Antonellis, S., Joppolo, C.S., Molinaroli, L. Simulation, performance analysis and optimization of desiccant wheels, Energy and Buildings, 2010; 42: 1386-1393.

[10] Capeluto, I.G., Perez, Y.V. Climatic considerations in school building design in the hothumid climate for reducing energy consumption, Applied Energy, 2009; 86 (3): 340-348.

[11] Alwaer, H., Clements-Croome, D.J. Key performance indicators (KPIs) and priority setting in using the multi-attribute approach for assessing sustainable intelligent buildings, Building and Environment, 2010; 45: 799-807.

[12] Alanne, K., Salo, A., Saari, A., Gustafsson, S-I. Multi-criteria evaluation of residential energy supply systems, Energy and Buildings, 2007; 39: 1218-1226.

[13] Moeck, M., Selkowitz, S.E. A computer-based daylight systems design tool, Automation in Construction, 1996; 5: 193-209.

[14] Jenkins, D., Newborough, M. An approach for estimating the carbon emissions associated with office lighting with a daylight contribution, Applied Energy, 2007; 84: 608-622.

[15] Tzempelikos, A., Athienitis, A.K. Integrated Thermal and Daylighting Analysis for Design of Office Buildings. In: ASHRAE Transactions, Vol. III, Part 1. Atlanta, Georgia, USA:

ASHRAE; 2005, pp. 227-238.

[16] Johnson, R., Sullivan, R., Selkowitz, S., Conner, C., Arasteh, D. Glazing energy performance and design optimization with daylighting, Energy and Buildings, 1984; 6: 305-317.

[17] Bokel, R.M.J. The effect of window position and window size on the energy demand for heating, cooling and electric lighting, In: Proceedings 10th International IBPSA Conference. Beijing, China: International Building Performance Simulation Association; 2007, pp. 117-121.

[18] Lee, E.S., Tavil, A. Energy and visual comfort performance of electrochromic windows with overhangs, Building and Environment, 2007; 42: 2439-2449.

[19] Ochoa, C.E., Capeluto, I.G. Strategic decision-making for intelligent buildings:

Comparative impact of passive design strategies and active features in a hot climate, Building and Environment, 2008; 43: 1829-1839. 
[20] European Commission Enterprise and Industry portal, National Building Regulations in the Netherlands (online documentation). Available from:

ec.europa.eu/enterprise/sectors/construction/files/compet/national-building-regulations/prcnl_en.pdf (accessed January 2012).

[21] CIBSE-Chartered Institution of Building Services Engineers. Degree-days: Theory and application, Document TM41:2006 (online documentation). Available from: cibse.org (accessed August 2011).

[22] Toftum, J., Andersen, R.V., Jensen, K.L. Occupant performance and building energy consumption with different philosophies of determining acceptable thermal conditions, Building and Environment, 2009;44: 2009-2016.

[23] Achard, G., Laforgue, P., Souyri, B. Evaluation of radiative comfort in office buildings. In: Proceedings CLIMA 2000 Session 1. Brussels, Belgium: CLIMA; 30 August-2 September 1997.

[24] Newsham, G., Brand, J., Donnelly, C., Veitch, J., Aries, M., Charles, K. Linking indoor environment conditions to job satisfaction: a field study, Building Research and Information, 2009; 37(2): 129-147.

[25] Mardaljevic, J., Heschong, L., Lee, E. Daylight metrics and energy savings, Lighting Research and Technology, 2009; 41: 261-283.

[26] Reinhart, C.F., Mardaljevic, J., Rogers, Z. Dynamic daylight performance metrics for sustainable building design, Leukos, 2006; 3(1): 1-25.

[27] Assaf, L. Components of innovative glazing performance. In: Proceedings Right Light 4, Vol. 1. Copenhagen, Denmark: International Association for Energy Efficient Lighting; 1997, pp. 207-210.

[28] CIBSE-Chartered Institution of Building Services Engineers. CIBSE Guide F: Energy efficiency in buildings, 2nd Ed, London: CIBSE; 2006.

[29] Rhea, M. (ed.) Lighting Handbook: Reference and application, 9th Ed, New York: IESNAIlluminating Engineering Society of North America; 2000.

[30] BREEAM, BRE Global Limited. Scheme Document SD 5055, BREEAM offices 2008, issue 4. Hertfordshire, UK, 2010. 315 pages. (Electronic document). Available from: http://www.breeam.org/ (accessed August 2011).

[31] Mardaljevic, J. Simulation of annual daylighting profiles for internal illuminance, Lighting Research and Technology, 2000; 32: 111-118.

[32] Nabil, A., Mardaljevic, J. Useful daylight illuminances: A replacement for daylight factors, Energy and Buildings, 2006; 38: 905-913. 
[33] Osterhaus, W.K.E. Discomfort glare assessment and prevention for daylight applications in office environments, Solar Energy, 2005; 79: 140-158.

[34] Bellia, L., Cesarano, A., Iuliano, G.F., Spada, G. Daylight glare: A review of discomfort indexes. In: Visual quality and energy efficiency in indoor lighting: Today for tomorrow, International Workshop, 31 March 2008, Rome, Italy. Ente per le Nuove Tecnologie, L'Energia e L'Ambiente, ENEA. Available from: www.fedoa.unina.it/1312/1/Bellia_paper.pdf (accessed July 2011).

[35] Boyce, P.R. Human factors in lighting. 2nd Edition, London: Taylor and Francis; 2003.

[36] Baker, N., Fanchiotti, A., Steemers, K. Daylighting in architecture: a European handbook, London: James and James Science Publishers; 1993.

[37] Nazzal, A.A. A new evaluation method for daylight discomfort glare, International Journal of Industrial Ergonomics 2005; 35: 295-306.

[38] Araji, M.T., Boubekri, M. Window sizing procedures based on vertical illuminance and degree of discomfort glare in building interiors, Architectural Science Review, 2008; 51(3): 252262.

[39] Wienold, J., Christoffersen, J. Evaluation methods and development of a new glare prediction model for daylight environments with the use of CCD cameras, Energy and Buildings, 2006; 38: 743-757.

[40] Andersen, M., Kleindienst, S., Yi, L., Lee, J., Bodart, M., Cutler, B. An intuitive daylighting performance analysis and optimization approach, Building Research and Information, 2008; 36(6): 593-607.

[41] Heijboer, D., Nellestijn, J. (eds.) Klimaatatlas van Nederland. De normaalperiode 19712000, Rijkswijk, the Netherlands: Elmar B.V.; 2002 (in Dutch).

[42] Van Dijk, D. REVIS Description reference office room for Radiance calculations, European Commission JOULE Programme Project: REVIS Daylighting products with redirecting visual properties. Delft, the Netherlands: TNO Building and Construction Research; July 2001 [16 pages, electronic document].

[43] Van Dijk, D. Reference office for thermal, solar and lighting calculations, IEA Task 27, Performance of Solar Facade Components. Delft, the Netherlands: TNO Building and Construction Research; September 2001 [45 pages, electronic document].

[44] United States Department of Energy. EnergyPlus Documentation, 2012. Available from: $\mathrm{http}$ :/apps1.eere.energy.gov/buildings/energyplus/energyplus_documentation.cfm (accessed January 2012). 
[45] Ditlevsen, O. Decision modeling and acceptance criteria, Structural Safety, 2003; 25:165191.

[46] Deb, K. Multi-objective optimization, In: Burke, EK, Kendall, G (eds.) Search methodologies. Introductory tutorials in optimization and decision support techniques. New York: Springer; 2005.

[47] Bluyssen, P.M., Aries, M.B.C., van Dommelen, P. Comfort of workers in office buildings: The European HOPE project, Building and Environment, 2011; 46(1): 280-288. 